\title{
Letter of response: Evidence for the existence of a communication between the eye and the brain?
}

\author{
H. Cebula ${ }^{1}$ (D) I. Ollivier ${ }^{1} \cdot$ J. Todeschi $^{1} \cdot$ F. $^{\text {Proust }}{ }^{1}$
}

Received: 5 May 2017 / Accepted: 9 May 2017 /Published online: 18 May 2017

(C) Springer-Verlag Wien 2017

We have read with interest the letter to the editor: Evidence for the existence of a communication between the eye and the brain?

First, we thank Wostyn et al. for their suggestions and comments.

Wostyn et al. described an alternative hypothesis for the existence of a communication between the eye and the brain to explain intraocular silicone migration into the subarachnoid space [6].

This intraocular silicone migration represents a consequence of the possible continuum between the subarachnoid space surrounding the optic nerve and the subhyaloid space [2]. Terson syndrome (TS) is another possible consequence of this continuum with another direction. The TS was defined by an increase of the intracranial pressure (ICP) transmitted directly through the optic nerve sheath resulting in venous hypertension and bleeding of the retinal vessels [4]. Others speculated that the subarachnoid space is pressed directly into the orbital cavity via the optic nerve sheath. The combination of these two mechanisms seemed logical.

Wostyn et al. proposed another explanation of the silicone migration by a paravascular communication between the surrounding of the retinal vascular system and the surroundings of the central vessels in the optic nerves with a possible transmission of the fluid from the vitreous cavity to the subarachnoid space. This

\section{H. Cebula}

helene.cebula@hotmail.fr

1 Department of Neurosurgery, University Hospital of Strasbourg, Avenue Moliere, 67000 Strasbourg, France hypothesis supports arguments for the discussion of the possible existence of the continuum [6].

Different predisposing factors need to be added to explain these two syndromes $[1,3]$. The most important factors could be the increased intraocular pressure for the silicone migration into the brain or the increased intracranial pressure for the TS with a possible positive correlation between the TS and ICP [5]. This "paravascular retino-orbital continuity" could permit a transmission of fluid with two possible directions: from the subarachnoid space to the vitreous cavity and from the intraocular space to the subarachnoid space [6].

\section{References}

1. Ascaso FJ, Grzybowski A (2017) Subarachnoidal migration of intraocular silicone oil. Acta Neurochir 159:807. doi:10.1007/s00701017-3131-2

2. Cebula H, Kremer S, Chibbaro S, Proust F, Bierry G (2017) Subarachnoidal migration of intraocular silicone oil. Acta Neurochir 159:347-348. doi:10.1007/s00701-016-3011-1

3. Cebula H, Proust F (2017) Letter of response: subarachnoid migration of intraocular silicone oil. Acta Neurochir 159:809. doi:10.1007/ s00701-017-3132-1

4. Czorlich P, Skevas C, Knospe V, Vettorazzi E, Richard G, Wagenfeld L, Westphal M, Regelsberger J (2015) Terson syndrome in subarachnoid hemorrhage, intracerebral hemorrhage, and traumatic brain injury. Neurosurg Rev 38:129-136; discussion 136. doi:10.1007/ s10143-014-0564-4

5. Joswig H, Epprecht L, Valmaggia C, Leschka S, Hildebrandt G, Fournier JY, Stienen MN (2016) Terson syndrome in aneurysmal subarachnoid hemorrhage - its relation to intracranial pressure, admission factors, and clinical outcome. Acta Neurochir 158:1027-1036. doi:10.1007/s00701-016-2766-8

6. Wostyn P, De Groot V, Van Dam D, Audenaert K, De Deyn PP, Killer HE (2016) The Glymphatic system: a new player in ocular diseases? Invest Ophthalmol Vis Sci 57:5426-5427. doi:10.1167/iovs.1620262 